\title{
Multiple sclerosis associated with water intoxication
}

\author{
D.F. D'Costa, P. Weston and P.A. Millac
}

Department of Neurology, Leicester Royal Infirmary, Leicester LE1 5WW, UK.

\begin{abstract}
Summary: We present a case of well documented multiple sclerosis which presented with the syndrome of inappropriate antidiuretic hormone secretion, following an exacerbation of the disease. This is a poorly documented association.
\end{abstract}

\section{Introduction}

The syndrome of inappropriate antidiuretic hormone (SIADH) secretion has been described in a wide range of neurological and other disorders. A single instance of SIADH with possible multiple sclerosis (MS) was reported over 10 years ago. ${ }^{1}$ The diagnosis of MS in that case was clinical and not supported by laboratory evidence. We wish to add a well documented case of MS complicated by SIADH.

\section{Case history}

A 57 year old West Indian man was admitted as an emergency with a 3 day history of an acute confusional state. He developed MS in 1968 presenting initially with an optic neuritis and had a relapsing and remitting history, resulting in a spastic paraplegia and retention of urine requiring a long term urinary catheter. The diagnosis of MS was corroborated by abnormal visual evoked responses and oligoclonal bands in his cerebrospinal fluid. There was no serological evidence of HTLV 1 infection. Insulin dependent diabetes was diagnosed in 1970. One week prior to this admission, he developed pain behind his left eye with total loss of vision. This was diagnosed as an optic neuritis by the ophthalmologists. Three days afterwards his mental state and conscious level deteriorated culminating in his admission. He was on Humulin M2 40 units at night, baclofen $10 \mathrm{mg}$ three times a day, carbamazepine $200 \mathrm{mg}$ twice a day and amitriptyline $75 \mathrm{mg}$ at night. He had been on these drugs, in these doses, for more than 6 months and no changes were made to the regimen during his stay. He had never been on long term corticosteroids.

Correspondence: D.F. D'Costa, M.R.C.P., Dept. of Medicine, Leicester General Hospital, Leicester, UK. Accepted: 15 March 1990
On examination he was apyrexial; he was clinically euvolaemic - his blood pressure was $110 / 70 \mathrm{mmHg}$ with no postural drop; his chest was clear. He scored $9 / 15$ on the Glasgow Coma Scale. Neurological examination showed a spastic paraparesis as before, with no new features. Investigations showed a serum sodium of $109 \mathrm{mmol} / \mathrm{l}$, potassium $4.7 \mathrm{mmol} / \mathrm{l}$, urea $3.5 \mathrm{mmol} / \mathrm{l}$ and creatinine $56 \mathrm{mmol} / \mathrm{l}$. His serum albumin was $30 \mathrm{~g} / \mathrm{l}$ and total protein $62 \mathrm{~g} / \mathrm{l}$. Serum osmolality was $235 \mathrm{mosmol} / \mathrm{kg}$ and urinary osmolality was $275 \mathrm{mosmol} / \mathrm{kg}$. Other investigations including blood-count, sugar, lipids and chest X-rays were normal. A lumbar puncture and computerized tomographic (CT) head scan were also normal.

He was restricted to 1 litre of fluid a day. His conscious level gradually improved over the next week and prior to discharge his sodium was $137 \mathrm{mmol}$ and serum osmolality $280 \mathrm{mosmol} / \mathrm{kg}$. When discharged he was fully alert and orientated.

\section{Discussion}

This patient had an exacerbation of his MS, as shown by the episode of retrobulbar neuritis, followed 3 days later by progressive confusion. The hyponatraemia and low plasma osmolality with an inappropriately elevated urine osmolality, in a euvolaemic patient, confirmed a diagnosis of SIADH. Other neurological causes of SIADH such as meningitis, cerebral abscess, encephalitis, stroke, head injury, and subdural haematoma ${ }^{3}$ were excluded. Both carbamazepine ${ }^{2}$ and amitriptyline ${ }^{3}$ have been associated with SIADH which resolves on discontinuation of the therapy. However, this patient improved without altering his drugs so making his medication an unlikely cause for the SIADH. We believe the exacerbation of MS was reponsible for the SIADH. The mechanism of ADH release is not known but may result from hypothalamic demyelination which has been 
reported. ${ }^{4}$ This case is consistent with the observation that SIADH tends to occur during the active phase of cerebral disorders. ${ }^{5}$

\section{References}

1. Apple, D., Kreines, K. \& Biehl, J.P. The syndrome of inappropriate antidiuretic hormone secretion in MS. Arch Intern Med 1978, 138: 1713-1714.

2. Stephens, W.P., Espir, M.L., Tattersall, R. et al. Water intoxication due to carbamazepine. $\mathrm{Br}$ Med $J$ 1977, 1: 754-755.

3. Ledingam, J.G.G. Syndrome of inappropriate ADH secretion. In: Wetherall, D.J., Ledingham, J.G.G. \& Warrell, D.A. (eds). Oxford Textbook of Medicine 2nd edition, vol. 2. Oxford Univeristy Press, Oxford, 1987, 18.26-18.27.
We report this case to alert practitioners that confusion in MS as in other disorders of the central nervous system may be due to SIADH.
4. Kamalan, N., Keesey, R.E. \& Zurheim, G.M., Lateral hypothalamic demyelination and cachexia in a case of malignant multiple sclerosis. Neurology 1975, 25: 25-30.

5. Bartter, F.C. \& Schwartz, W.B. The syndrome of inappro- ڤ priate secretion of antidiuretic hormone. Am J Med 1967, 42: 790-806. 